\title{
User Perceptions of Social Media: A Comparative Study of Perceived Characteristics
} and User Profiles by Social Media

\author{
Sylvia M. Chan-Olmsted, University of Florida, USA \\ Moonhee Cho, University of South Florida, USA \\ Sangwon Lee, Kyunghee University, Korea
}

\begin{abstract}
Despite the proliferation of social media and the widespread adoption of these diverse communication tools, there is a lack of studies that conceptualize the characteristics of social media as perceived by users and compare the perceived characteristics or benefits of different social media types. This study examines the user perceptions of six main groups of social media-blogs, micro-blogs, social networks, wikis, forums, and content communities-on five dimensions: participation, commonality, connectedness, conversationality, and openness. User profiles are also investigated to assess the role of demographics and usage in such perceptions. The results of a national consumer panel survey show that different social media applications are perceived differently and social media usage patterns, gender, and age affect these perceptions.
\end{abstract}

Keywords: Social media, user perceptions, perceived characteristics 


\section{Introduction}

As the World Wide Web continues to evolve, the usage pattern of Internet surfers has shifted from that of passive readings to active building of contents, illustrating the user-centric, interactive, and collaborative nature of Web 2.0 (Sharma, 2008). Among all platforms enabled by the advancement of Web 2.0, social media is perhaps the most significant application that has grown exponentially in many population segments (Barnes, 2009; Bernoff, Pflaum, \& Bowen 2008; Corbett 2009; Miller, 2009). Nielsen (2009) showed that social networking sites have overtaken personal email and become the fourth most popular Internet activities, following search, portals, and PC software applications. In fact, a billion of people have accounts on Facebook as of October 2012 (The Huffington Post, 2012). It was suggested that, rather than replacing face-to-face communication or interaction, social media provides new opportunities to develop relationships and enhances one's social connections with others through sharing of information (Pilch 2009; Waters, Nuttall, \& Gelles, 2009). In essence, no longer the domains of younger generation and tech-savvy consumers, social media has entered the "mainstream" society with promising social utilities (Stephen \& Galak, 2009, p. 3).

Proliferation of social media and the widespread adoption of these media tools have brought dramatic changes in the business environment. Forrester Research reported that $75 \%$ of online consumers are currently social media users (Nail, 2009). Furthermore, consumers' desire to interact with marketers is high. According to a survey conducted among a sample of American social media users, $93 \%$ of them indicated that a company should have a presence in social media and about $85 \%$ said that a company is required to not only have a presence in social media but also interact with customers through social media (Larrumbide, 2008). Though still struggling to understand how social media might be used to its full potential, most companies, large and small, have actively utilized various social media applications as an advertising tool (Paine, 2009). For example, according to eMarketer, U.S. companies will spend $\$ 3.08$ billion to advertise on social networking sites in 2011, a 55\% increase from the previous year (eMarketer, 2011). Nevertheless, it seems that, instead of considering the potentially diverse functions offered by different social media platforms and basing their advertising decisions on how users adopt and perceive each type of social media, the trend seems to be simply utilizing the most popular social media sites like Facebook, LinkedIn, and Twitter (Stelzner, 2009). 
The premise of the current study is that "social media" is a collective term describing a great number of applications that enable users to connect, interact, and share contents. From popular social networking sites like Facebook, photo sharing sites like Flickr, social bookmarking sites like Digg, to micro-blogging sites like Twitter, different social media applications, though sharing some underlying commonalities, offer different core utilities, satisfy different primary needs, and have different levels of popularity. For example, market reports have suggested that Twitterers mostly consume news, MySpace users want games and entertainment, Facebookers are into news and community and Digg's users have a mixed bag of interests (Van Grove, 2010). Yet there has been a lack of research conceptualizing the characteristics of different social media platforms as perceived by users. Such fundamental knowledge would contribute to our understanding of the factors affecting the effectiveness of social media in achieving specific advertising or marketing communications goals and provide insight on the linkage between the structural differences of various social media platforms and their communication outcomes. Even when technologies have integrated additional functions into each social media platform (e.g., Facebook with the photo sharing capability), different platforms are meant to have certain differentiable core functions. Accordingly, the current study proposes a conceptual framework illustrating the various characteristics of social media and empirically assessed the differential perceptions of major social media types as perceived by their users. Basic user profiles are also examined to gauge the role of demographics and social media usage in such perceptions.

\section{Literature Review}

\section{Definition and Types of Social Media}

Due to its fast evolving nature and diversity in delivery platforms, there is a lack of agreement on what social media is. From an instrumental aspect, Drury (2008) defines social media as "online resources that people use to share content: video, photos, images, text, ideas, insight, humor, opinion, gossip, news" (p.1). Emphasizing people's behaviors when engaged in social media, Dykeman (2008) defined social media as "the means for any person to: publish digital, creative content; provide and obtain real-time feedback via online discussions, commentary and evaluations; and incorporate changes or corrections to the original content" (p.1). Marchese (2007) distinguished social media from traditional media by stating that social media "is not the media itself, but the system of discovery, distribution, consumption and conversation surrounding the media." (p. 1). Safko and Brake (2009) further considered 
social media as "activities, practices, and behaviors among communities of people who gather online to share information, knowledge, and opinions using conversational media. Conversational media are Web-based applications that make possible for one to create and easily transmit content in the form of words, pictures, videos, and audios" (p. 6). In general, social media can be understood as online platforms for the interaction, collaboration, and creating/sharing of various types of digital contents (Eisenberg, 2008; Universal McCann, 2008). Social media, comparing to traditional media, allows people to actively engage in a communication process not only as information receivers but also as message creators. The online applications are designed to facilitate information sharing, knowledge distribution, and opinion exchanges.

Just as much as its variety of definitions, social media includes a diversity of applications with different core functions and structures. The most popular and high profile social media, Social Network Sites (SNSs), allows people to create their own Web pages and then share contents and communicate with online friends (Mayfield, 2008). Unlike other social media, SNSs let users articulate their social networks by providing visible lists as well as traversing them easily (Boyd \& Ellison, 2007). Hence, rather than expanding networks to new people, offline acquaintances are the primary communication groups within SNSs and the main activities are based on relationship management. Best examples of SNSs are Facebook, MySpace, Bebo, and Linked In.

Weblog or blog is a Web information sharing technology (Boulos, Maramba, \& Wheeler, 2006). Functioning as an online journal, blogs have unique date entries about an issue with the most recent comments shown first in reverse chronological order (Mayfield, 2008). Composed of text, image, videos, commentary, and links to other Web sites, the contents are contributed by individuals or a group of both professionals and amateurs. Mayfield (2008) distinguished blogs from generic Websites in terms of tone, topic, and ease of inserting links and trackbacks. Moreover, blogs are easily subscribed through RSS technology. Popular blogs like Huffingtonpost.com reached over 5.6 million readers in 2009 (Lipsman, 2009).

Combining the characteristics of both SNSs and blogs, micro-bloggings allow users to write brief updates - up to 140 characters - through the mobile text message, Instant Messaging, and a desktop application (Mayfield, 2008). Twitter and Jaiku are examples of micro- 
blogging services. Applying a light-weight and easy form of communication, microbloggings offer users an efficient means of sharing information about their activities and opinions (Java et al., 2007).

Wiki is a communication mechanism to create Web-based contents that require group collaboration (Mayfield, 2008; Pfeil, Zaphiris, \& Ang, 2006). By allowing users to easily create, modify, and disseminate information, anyone can participate in elaborating information as an author or editor (Pfeil et al., 2006). Due to the absence of an actual monitor for content quality, wikis sometimes contain inaccurate information which can be quickly halted and reversed to a previous version (Viégas, Wattenberg, \& Dave, 2004). Collaborative authorship and version control are the key criteria for a wiki (Emigh \& Herring, 2005). Wikipedia is the most well-known example of wikis.

Forums or online message boards, the longest established form of social media, are usually developed with specific topics and interests, such as music, car, and new gadgets, in mind (Mayfield, 2008). Rather than idle chats, dynamic debates, active advising, and news sharing on specific topics characterize online forums/message boards. Commonly used in education, it is considered a virtual learning place that shares common interests and topics (Thomas, 2002). Online forums are usually moderated by an administrator whose job is not to lead the discussion but to delete inappropriate contents or spam. The major difference between forums and blogs places on who are in charge of leading the sites; blogs are maintained by a clear owner while a forum is typically initiated by its members (Mayfield, 2008).

While sharing SNSs' traits of requiring registration to obtain a personal home page and connect with friends, content communities focus on sharing a certain type of content, such as photo, video, music, and bookmark (Mayfield, 2008). Contents are easily shared by a networked group with a tag to the content. Flickr, YouTube, and del.icio.us are widely known content communities for photos, videos, and bookmarks, respectively. Though podcasting is sometimes considered a type of social media that distributes audio or video files to users who have a mobile or digital device and offers subscribing feature through RSS to the subscriber community (Cebeci \&Tekdal, 2006; Mayfield, 2008), it is not included in this study because of its primarily one-directional distribution of content with very limited interactivity. 


\section{Characteristics of Social Media}

While social media is a generic term covering different online platforms with various attributes, communication formats, and sociability functions, there are certain characteristics that all social media applications fundamentally share. Mayfield (2008) identified five specific characteristics that underline the operations of all social media: participation, openness, conversation, community, and connectedness. Further literature on social media characteristics is presented next using this framework of the fundamental dimensions of social media.

Participation. One of the most distinctive characteristics of social media is its participatory nature that allows interested parties an opportunity to engage in an interaction. By encouraging contributions and feedback from everyone who is interested, social media blurs the line between media and audience (Mayfield, 2008). Emphasizing the "social" element of the social media, Drury (2008) argued that social media allows people to share and engage with each other so that they enable content shared "to become more democratized than ever before" (p. 274). While varying in the degree of participation, social media has been employed by a number of organizations in order to facilitate a participative culture (Rosso et al., 2008).

As a major component of interactivity, participation can be defined as "the extent to which senders and receivers are actively engaged in the interaction as opposed to giving monologues, passively observing, or lurking" (Burgoon et al., 2000, p. 36). In a sense, participation here can be seen as action-oriented interactivity. Koh and Kim (2004), adopted the organizational citizenship behaviors (OCB) model, regarded participation as a voluntaryhelping behavior in virtual community (e.g., providing valued information and knowledge for help-seeking members). Specifically, participation can be measured through the OCB engagement of social media users as well as the frequency of visits, length of stay in social media (Koh \& Kim, 2004).

Conversationality. Compared to traditional media, social media enables two-way conversations rather than one-directional transmissions or distributions of information to an audience (Mayfield, 2008). While traditional channels, such as television, radio, newspaper, and magazine, only deliver a linear communication mechanism, the Internet provides a non- 
linear or two-way communication environment (Rowley, 2004). Web 2.0 further enhances the capacity and speed of such dialogic loops, making conversationality a central theme of social media. Whereas participation is behavior/action-oriented interactivity, conversationality is rooted in communicational aspect of interactivity. As Rafaeli (1988) asserted, "conversationality" is the ideal of interactivity, and thus an important virtue of social media. It is well documented that the degree of conversationality varies by social media types. For example, while SNSs like Facebook offer numerous communication components for conversations between users, micro-blogging tools like Twitter and content communities like YouTube have comparatively more limited conversationality or two-way communication because of the core utilities and structures inherent in these social media (Pilch, 2009). How may the degree of conversationality be measured? Some scholars suggest that two-way communication may be examined by focusing on the key dimensions of "feedback" as a component of interactivity, active control, and synchronicity (Liu, 2003; Liu \& Shrum, 2002).

Connectedness. Even though the physical presence is considered to be ideal in social relations (Stafford, Kline, \& Dimmick, 1999), interpersonal ties can be maintained by not only face-to-face communication but also mediated interaction via communication technologies (Stafford et al., 1999; Wellman \& Gulia, 2003). By providing Web links to other sites, resources, and people, social media allows media users to move from one point to others in cyberspace, and offers connectedness to its users (Mayfield, 2008).

Social connectedness may be defined as "interpersonal, community, and general social ties" (Teixeira, 1992, p. 36). Considering the concept as a type of relational scheme, Lee and Robbins (1998) characterized social connectedness as a pattern of active and trustful interpersonal behaviors. Perceived connectedness is positively related to closeness and identification with others (Lee, Draper, \& Lee, 2001). In this sense, people with high connectedness feel close and amiable with others, identify with them, and engage with social groups whereas people with low connectedness often experience psychologically distant from others, feel themselves as outsiders, and are not adequate for social situations. From a mediated communication context, connectedness enables people to tie to the outside world and to easily expand their experience (Ha \& James, 1998). For example, experiencing connectedness to the outside world with appropriate mapping of hypertext and images, Web 
site visitors feel virtually present (Steuer, 1992). The fundamental "networking" mechanism present in all social media further magnifies the effect of connectedness on the Internet. It was suggested that, in addition to the ability of social media such as SNSs to connect individuals with acquaintances as well as strangers, the public display and articulation of one's connections which often result in new connections between more individuals is what makes social media unique (Boyd \& Ellison, 2007).

Community and Commonality. Social media allows individuals and organizations to identify and communicate with the people whom they want to be associated with. That is, it offers a mechanism for individuals and organizations to form communities quickly and to develop relationships effectively with others who share some commonality with them (Mayfield, 2008). In fact, many have regarded social media as an effective means of developing communities. For example, most SNSs were launched to support niche demographics in an intimate, private community, such as the early Facebook for college students (Boyd \& Ellison, 2007). Nevertheless, it is important to differentiate community from commonality. While social media helps foster communities, its essence is not simply on building communities which are more continuous and regular in nature, and centered on a concept or common goal, as opposed to a collection of content. For example, viewers that post various online comments on a news story or video have something in common but might not necessarily be seen as belonging to a community. In other words, social media provides an effective means of developing communities, but its core utility is in linking individuals and organizations with others that share a certain commonality, as determined by their temporal needs and interests at the time of interaction.

Openness. Another evident characteristic of social media is its openness to user feedback and participation by having few barriers to accessing information or making comments (Mayfield, 2008). Meadows-Klue (2007) asserted that Web is a "near-frictionless media channel along which anything can flow" (p. 246), while most channels have frictions or barriers to the flow of information and knowledge in most surfaces. Most social media contains limited flow barriers, both in applications and technological transferability, so information can easily travel between sources and users and among users (Meadows-Klue, 2007). The openness characteristic is enhanced by social media's networking philosophy and the availability of easy-to-use mechanisms for creating and sharing contents. The evidence of 
openness is prevalent as people, especially the younger generation, share their lives online via social media sites like Facebook, Flickr, and Twitter, and organizations use corporate blogs to distribute information and receive feedback.

Depending on their structures, some types of social media might be perceived to be more open than others. For example, forums and online message boards that are organized by specific communities might be seen as less open than micro-blogging application like Twitter that anyone can sign up for. How may the degree of openness in social media be measured beyond its technological nature? In a communication context, Rogers (1987) suggested openness to involve three types of behavior: requesting information, receiving information, and acting on information received. A study explored the difference in the act of communication openness among various peer types found that communication openness is higher among peers who share mutual work/interests or feedback (Myers et al.,1999). It seems that the essence of openness, either through technological or cultural means, in social media may be defined by the perceived "ease" of giving and receiving contents, information, and comments by its users.

\section{Characteristics of Social Media Users}

As social media begins to draw attention from both academy and business practices, scholars have begun to explore the characteristics of social media users and motives of new media use. Yet, most studies have been limited to a specific type of social media or usage of SNSs, especially among the younger age group (i.e., Baker \& Moore, 2008; Barker, 2009; Ellison, Steinfield, \& Lampe, 2007; Raacke \& Bonds-Raacke, 2008; Ross et al., 2009; Valenzuela, Park, \& Kee, 2009).

In general, it was found that young people have been in the front line in creating and sharing content in new media (Pew Research Center, 2005; 2009). As social media continues to evolve, the pattern of social media use is also changing. According to Pew Research Center (2010), the popularity of blogs among adults over 30 has increased since 2006 while blogging of teens and young adults has dropped. Instead of blogging, the Millennial generation and adults under 30 are becoming more active in their use of SNSs. Indeed, almost $75 \%$ of teens and young adults use SNSs whereas $40 \%$ of adults over 30 use this type of social media (Pew Research Center, 2010). Illustrating the importance of the connectedness characteristic, 
Barker (2009) found that older adolescents who reported a disconnection from their peer groups and having negative collective self-esteem use SNSs to fulfill companionship. In a sense, SNSs allow older adolescents to seek identification with others who they might have an easier time connecting with. The need to interact with others through online communication platforms has been well documented for older adults as well. Utilizing both conversation analysis of the SeniorNet forum and survey with the forum users, Wright (2000) found the crucial role of online communication for aging individuals in providing social support that allows the forum users to feel a sense of community as well as to share life events.

Whereas there is no significant difference in the amount of social media use and sharing of user-generated media content between males and females (Pew Research Center, 2005; 2007; 2009), studies have shown some dissimilarity in social media preferences and motives by gender (Barker, 2009; Joiner et al., 2006; Pew Research Center, 2007; Raacke \& BondsRaacke, 2008). Pew Research Center (2007) reported that boys use SNSs to expand their networks by making new friends, while the major purpose of SNSs for girls is to maintain existing friendships. Raacke and Bonds-Raacke (2008) also found similar results that males are more likely to use SNSs with the purpose of flirting and learning about events. A research to explore motivations for SNSs users revealed that the primary motives to use the sites for females are communication, entertainment, and passing time (Barker, 2009). An empirical study found that women are more likely to engage in SNSs than men, reflecting that women prefer person-to-person communication online to men (Hargittai, 2007). On the other hand, males' motivations have roots in social compensation, learning, and social identification gratifications. In other words, females use SNSs for relational purposes more frequently than their male counterpart.

Given that most social media research has focused on young adults, there is a lack of studies that explore the effects of other demographic variables, such as ethnicity, occupation, and socioeconomic status. In general, high-income householders and highly educated people are more likely to be heavy Internet users and earlier adopters (Pew Research Center, 2003). Nevertheless, Hargittai (2007) failed to find differences in social media use by ethnicity or parental education which was used as a proxy of socioeconomic status. Hargittai did observe that different ethnic groups and parental education groups have different preferences on specific social media sites. For instance, Hispanic students tend to prefer MySpace to 
Caucasians and students whose parents have a college degree are more likely to use Facebook than students whose parents have no college degrees. In addition, Internet accessibility at the place of friends and family increases the likelihood of social media use (Hargittai, 2007).

Considering the characteristics of social media discussed, the diversity of social media types, and the potential role of user profiles in affecting these factors, this study proposes the following research questions:

RQ1: How user perceived the various types of social media differently based on the media dimensions of participation, openness, conversationality, connectedness, and commonality?

RQ2: What user characteristics play a role in their usage of social media?

RQ3: What user characteristics play a role in their differential perceptions of social media?

\section{Research Method}

\section{Sample and Data Collection Procedure}

To ensure that the perceptions of social media are based on a diverse population of users, this study employed a national consumer panel with online access for its Web-based survey. As Internet connection is a necessary condition for the use of social media, online survey is an appropriate data collection method. With the popularity of the Internet, online surveys have been adopted to collect data in social sciences for years (Ballard \& Prine, 2002; Schonlau, Fricker, \& Elliott, 2002; Wimmer \& Dominick, 2006). About 1,623 adults randomly selected from a combination of national consumer panels maintained by a leading market research firm were contacted via email with the survey link during the period between March 4 and March 9, 2010. The sample included U.S.-based adults who have opted in to participate in a consumer panel for small premium rewards and who have not participated in any online surveys in the past two weeks.

Prior to the main survey, a pre-test was instituted on 12 undergraduate students to refine the instrument's design and wording. Since the purpose of the study is to understand real users' perceptions of social media characteristics and compare their perceived differences of the characteristics among social media types, two qualifying questions were introduced to 
identify the respondents who have actual personal experience or knowledge of the social media examined. Specifically, only two groups of the panelists responded to the survey email were qualified to participate: 1) those who have used all six types of social media identified, and 2) those who have used at least three of the six social media types "and" are familiar with the rest. Note that to be selected to participate, the panelists did not have to be a regular user of all the social media; they just had to have at least one user experience with each of the six platforms identified or with half of the social media types and some knowledge of the others. The screening condition was instituted to strike a balance between ensuring the assessment of perceptions that are based on realistic usage experience and avoiding including only heavy social media users. Among the 1623 panelists, 735 have not used at least three types of social media and 290 have used at least three types of social media but are unfamiliar with the rest. Finally, 379 panelists completed the survey. Excluding 39 invalid responses, a total of 340 surveys were used for the analysis, resulting in an incidence rate of $21 \%$.

Of the 340 valid cases, 269 have used all the social media types before, while 71 have used at least half of the social media types and are familiar with those they have not used before. Among the final sample, 65\% are female; 5.9\% are between 18-24, 21.8\% 25-34, 20.6\% 35$44,25.9 \% 45-54,19.1 \% 55-64$, and $6.8 \% 65$ or older. Over $57 \%$ are married. While $87.9 \%$ are Caucasians, five minority groups comprise of the other $12.1 \%$. In terms of education, about $18 \%$ completed high school, but over $41 \%$ completed college and $15 \%$ with advanced degrees. Using the census occupation categories, the largest percentage came from management and professional occupations (22\%). The income distribution is fairly even with $44 \%$ earning $\$ 45,000$ or less and $25 \%$ over $\$ 75,000$. The overall demographic composition is relatively diverse. In terms of social media usage, the respondents use SNSs most frequently $(M=5.10, \mathrm{SD}=1.76 / 7$-point scale $)$, followed by content communities $(M=4.40, \mathrm{SD}=1.69)$, wikis $(M=4.10, \mathrm{SD}=1.66)$, forums $(M=4.04, \mathrm{SD}=1.68)$, blogs $(M=3.62, \mathrm{SD}=1.71)$, and micro-blogging $(M=3.04, \mathrm{SD}=1.96)$.

\section{Measures}

A set of measurement scales for five different characteristics of social media was gleaned from a variety of communication and psychology literature. Specifically, each survey respondent received five sets of social media characteristic measurement scales for each of the six distinct social media types, including social network sites, blogs, wikis, forums/online 
message boards, content community, and micro-blogging. For all these measures, respondents were asked how they feel when using a certain type of social media, applying a 7-point Likert scale, where 1 represented strongly disagree, 4 represented neither agree nor disagree, and 7 represented strongly agree.

Among the five media characteristics, participation was measured by four scales adopted from Koh and Kim (2004). Since the original scales were designed to measure virtual community participation, the study selected and refined the items that are most applicable to the social media context. Along with the four items, one-item scale that literally describes the characteristic was also constructed to serve as the validation variable of the other scales. The average of Cronbach's alpha of the five scales measuring participation was .95 (see Table 1). The openness scales were adopted from Rogers's (1987) organizational communication study. Because the original scales were designed to measure perceived communication openness among members of an organization, four items that best suited for assessing this construct in the social media context were selected and refined based on the result of the pretest. Specifically, two items were used to address the openness of information exchange whereas the other two items dealt with the ease of giving or receiving comments. Another validating item was added to the mix. The average of Cronbach's reliability coefficient was .97 for these five scales.

The conversationality scales were developed from Liu's (2003) two-way communication items, a component of interactivity. Like other variables, the four most appropriate scales were adopted and refined to measure conversationality that focuses on the effectiveness of social media in dialogue engagement, feedback, and two-way communication. Including a validation item scale that addressed whether the specific social media type provides an environment to engage in conversation/interactive communication with other users, the average of Cronbach's alpha was .96.

The characteristic of connectedness was measured by four scales adopted from psychology literature by Lee et al. (2001). Based on the consideration of social media context and Chronbach's alpha of the previous study, four items including two reversed ones were used, as well as one-item scale for validation. While the average of Cronbach's reliability coefficient for the variable $(\alpha=.86)$ was relatively lower than other variables, all the items 
remained because the alpha was higher than .70 , an expected alpha criterion (Langdridge, 2004).

The commonality scales were developed by the authors based on the conceptual definition of commonality. Especially, scales were constructed to measure whether the social media users share common interests, ideas, and value. For example, respondents were asked, on a 7-point scale, whether they feel they can share common interests and ideas with others, whether they can find and interact with people like themselves, whether they feel a sense of belonging, and whether they can share their value and common goals with others. Including one validation scale - whether the specific type of social media provides a good environment for interacting with others who have something in common with the respondent- the average Cronbach's alpha of these five scales was 97 .

Demographic variables and usage measures were also presented prior to the items of social media characteristics. Basic demographic questions included gender, age, ethnicity, education, occupation, marital status, and annual house income. Also, survey respondents were asked to answer their frequency of social media usage for each type of social media and social media in general, employing 7-point Likert scales, ranging from 1 meant never, 4 meant average, and 7 meant all the time. The questions of social media usage also functioned as a filtering variable for disqualified respondents. Specifically, those who answered never used social media in general were excluded from the survey.

\section{Statistical Analysis}

Correlation analyses (Spearman's rho for rank-ordered variables and Point-biseriel correlation/Pearson $\mathrm{r}$ for gender) and ANOVA (for other categorical variables) were conducted to examine the association between user demographic variables and social media usage. Factorial MANCOVA was used to analyze the user variables on social media perceptions in the five characteristic dimensions (multiple independent variables on multiple dependent variables).

\section{Results}

\section{User Profiles and Usage of Social Media}

The correlation analyses found that younger adults tend to use SNSs much more frequently ( $r$ $=-.26, p<.000)$. In a slightly lesser degree, younger adults also tend to use blogs, content 
communities, and micro-blogging more frequently $(r=-.14, p<.01 ; r=-.12, p<.05 ; r=-$ $.11, p<.05)$. The demographic variable of age plays a significant role in the use of social media in general $(r=-.26, p<.000)$. Interestingly, while male users tend to use wikis more frequently $(r=-.12, \mathrm{p}<.05)$, female users use SNSs more frequently $(r=.15, p<.01)$. Income also plays a role in the users' social media usage. While individuals with higher incomes use online forums/message boards more frequently $(r=.13, p<.05)$, they tend to use SNSs less frequently $(r=-.15, p<.01)$. No significant association was found in social media usage and other education, marital status, and profession variables.

\section{User Perceptions of Social Media}

\section{Comparison of Perceived Characteristics by Social Media Types}

All six social media types were perceived to be above average in offering the feelings of participation, connectedness, conversationality, commonality, and openness (see Figure 1 and Table 2). Overall, SNSs tend to score the highest in all six media dimensions, followed by online forums/message boards, blogs, content communities, micro-blogging, and wikis, in that order. Comparatively, the dimension of "openness" seems to exhibit the least difference among the social media studied. Specifically, while SNSs and online forums/ message boards are seen as more open than others, wikis is regarded as the least open social media. This observation becomes even more evident for the dimension of "participation." Wikis, microblogging, and content communities are perceived to be much less participatory or connected than the two leading social media of SNSs and forums/online message boards. Finally, online forums/message boards are seen as much closer to the leading social media, SNSs, when it comes to the characteristics of conversationality and commonality.

From the perspective of comparing different characteristics on each social media type, "openness" seems to exhibit the highest mean scores among all other dimensions for all social media (see Table 2). Specifically, for SNSs, openness was the most evident perceived characteristics, followed by commonality, conversationality, participation, and connectedness. For blogs, openness has the highest mean score, followed by participation, commonality, connectedness, and conversationality. For wikis, openness was perceived to be the strongest characteristic, followed by connectedness, participation, commonality, and conversationality. For forums/online message boards, openness was the most evident dimension, followed by conversationality, commonality, participation, and connectedness. For content communities, 
openness has the highest mean score, followed by connectedness, participation, commonality, and conversationality. Finally, for micro-blogging, openness was again perceived to be the strongest characteristic, followed by connectedness, conversationality, participation, and commonality.

This study also examined all social media collectively using all media types' composite scores. It was found that openness was perceived to be the trait that most characterized social media in general $(M=5.01, \mathrm{SD}=1.01)$, substantially higher than that of participation $(M=$ $4.84, \mathrm{SD}=1.10)$, connectedness $(M=4.85, \mathrm{SD}=1.03)$, conversationality $(M=4.72, \mathrm{SD}$ $=1.09)$, and commonality $(M=4.81, \mathrm{SD}=1.11)$.

\section{Similarities in Perceived Characteristics among Social Media}

Correlation analyses reveal that there are some strong underlying relationships between certain dimensions of the social media examined (see Table 3). Specifically, participation and conversation, participation and commonality, and conversation and commonality are highly correlated across all six social media. In addition, openness and participation, openness and conversation, and openness and commonality are highly correlated in all social media but SNSs.

\section{Differences in Perceived Characteristics among Social Media}

Tests of one-way ANOVA reveal that there are statistically significant differences among the six types of social media in the perceived characteristic of participation, $F(5,2034)=23.24, p$ $<.001$, openness, $F(5,2034)=32.43, p<.001$, conversationality, $F(5,2034)=43.15, p$ $<.001$, commonality, $F(5,2034)=34.70, p<.001$, and connectedness, $F(5,2034)=15.77, p$ $<.001$.

\section{User Profiles and Differential Perceptions of Social Media}

Factorial MANCOVA reveals the effects of various user characteristics on the five perceived media dimensions for each social media and for social media in general. Using the five perceived characteristics as the dependent variables, the multivariate test reveals that for SNSs, social media usage is a significant variable that affects all five characteristics $(F=$ $16.92,19.40,12.35,18.00,17.64, p<.000$ for all). Gender also plays a role in participation $(F=6.75, p<.01)$, connectedness $(F=5.73, p<.05)$, and commonality $(F=5.12, p<.05)$, 
while age is associated with participation $(F=2.79, p<.05)$, connectedness $(F=2.96, p$ $<.05)$, conversationality $(F=2.49, p<.05)$, and commonality $(F=2.39, p<.05)$. Income $(F$ $=2.22, p<.05)$ contributes only to connectedness. As for blogs, both social media usage and gender are significant variables associated with all five characteristics $(F=15.98,14.11,8.69$, $15.49,14.31, p<.000$ for all; $F=8.60,8.65,8.80,5.04,7.69, p<.01, .01, .01, .05, .01)$, while income plays a role in participation $(F=2.35, p<.05)$ and connectedness $(F=2.26, p$ $<.05)$. As far as wikis is concerned, media usage was a significant variable for all five characteristics $(F=7.75,8.36,3.64,6.62,5.55, p<.000$ for all $)$, while gender plays a role in openness $(F=4.63, p<.05)$ and connectedness $(F=9.06, p<.01)$, and age in openness $(F=$ $2.37, p<.05)$, connectedness $(F=4.98, p<.000)$, and conversationality $(F=3.01, p<.05)$. For online forums/message boards, media usage and gender are significant for all characteristics $(F=17.13,19.64,11.37,17.23,18.73, p<.000$ for all; $F=4.10,8.28,10.86$, $4.93,7.27, p<.05, .01, .01, .05, .01)$, while age plays a role in participation $(F=2.35, p$ $<.05)$ and connectedness $(F=3.44, p<.01)$, and education in connectedness $(F=2.13, p$ $<.05)$. For content communities, media usage is still the only variable that is significant across all characteristics $(F=14.51,12.07,11.02,12.39,13.41, p<.000$ for all $)$, while gender and age both play a role in connectedness $(F=6.05, p<.05 ; F=3.61, p<.01)$. Finally, for micro-blogging, media usage is significant for all five characteristics $(F=19.41$, $22.06,14.70,19.95,19.92, p<.000$ for all). Age again plays a role in connectedness $(F=$ $2.82, p<.05)$. Overall, when all six types of social media are examined collectively, media usage was significant in affecting all five characteristics $(F=14.05,12.48,9.53,10.74,11.79$, $p<.000$ for all), while age makes a difference in participation $(F=2.55, p<.05)$, connectedness $(F=5.66, p<.000)$, and conversationality $(F=2.43, p<.05)$, and gender in connectedness $(F=5.97, p<.05)$.

Overall, openness is perceived to be the most evident quality characterizing all types of social media. Comparatively, participation is perceived most highly for blogs, connectedness for wikis and content communities, conversationality for online forums/message boards, and commonality for SNSs. In addition, SNSs and online forums/message boards are perceived to be superior to other social media types, especially to wikis, in all five characteristics. Interestingly, content communities, not online forums/message boards, were the second most frequently used social media next to SNSs. SNSs and online forums/message boards also share strong similarity in their media's conversationality and commonality. There seems to be 
some underlying relationship between different social media characteristics. Participation is highly associated with conversationality and commonality, commonality with conversationality, and openness with participation, conversationality, and commonality.

While SNSs were the most frequently used social media category, micro-blogging was the least used media type. The factor of social media usage appears to affect the perceptions for each social media type and social media in general. Gender, age, and, to a lesser degree, income and education, also play a role here. Consistent with previous findings, one's gender seems to make a difference in how he or she perceives the nature of most social media, especially in the dimension of connectedness. But it plays no role in the perception for microblogging. Age, on the other hand, is not associated with the perception for blogs, but affects all other social media, especially in the dimension of connectedness. Income only matters to the perceptions for SNSs and blogs, especially in the dimension of connectedness. Finally, education makes a difference in the perception of connectedness for online forums/message boards. In general, female and younger users tend to perceive SNSs highly in most characteristics. On the other hand, older users tend to perceive the information-centric social media like wikis, blogs, and online forums to offer more connectedness utility. The same holds true for more educated users in online forums and higher income users for blogs.

As far as demographic variables are concerned, consistent with previous findings, younger people are more active social media users. In addition, younger users tend to use SNSs, blogs, content communities, and micro-blogging more frequently. While men use wikis more frequently, women use SNSs more frequently. People with higher income also tend to prefer online forums/message boards as people with lower income prefer SNSs.

\section{Discussion}

While social media has become the driving force of Web 2.0 and been increasingly adopted by both Internet users and advertisers, it is often discussed as a collective medium with little reference to specific differences among various applications. The comparative examination of user perceptions on the five general characteristics of social media offers the first step in contrasting the perceived utilities of different major social media categories. The findings here empirically validated that social media users perceived various social media applications differently across multiple dimensions. While the characteristic of openness is the strong 
thread that links all social media together, each social media type, with its inherently unique structure and functions, offers something superior to the others (e.g., higher utility in connecting to the world for wikis and content communities, providing better conversational opportunities for online forums, and finding someone in common for SNSs). In designing an effective advertising campaign utilizing social media, one would need to take into consideration these inherent differences so to allocate the resources in accordance of the communications objectives. For instance, if an advertiser's goal is to form a like-minded, heavy user group as the advocacy agents of its product, SNSs might provide the most hospitable environment for such purposes at the initial stage. The observed linkage among participation, conversationality, and commonality also underscores the importance of implementing a social media program that offers ample opportunities for two-way communications between people of same interests to encourage active engagement of the users.

While it is intuitive that the more one uses a social media, the more he or she might see the value of the application, it is interesting to see that many demographic tendencies still ring true for the use of social media. Especially, this study points to the differential emphasis on the two core functions of social media: social (sociability) and media (content). While younger users see the "sociability" centric social media like SNSs as an effective means to connect to the world, older users view the "content" centric social media like wikis, forums, and blogs as better ways of connecting to the world. The differential emphasis in sociability and content among different age groups regarding social media has some interesting implications. First, there is a need to highlight different aspects of a social media communications campaigns depending on the target audience (e.g., interpersonal connections versus access and connections to things/facts).

Finally, as social media continues to evolve, it is important to note that technological changes have created an increasing convergence of functionality and features in many social mediating services. For instance, photo sharing and chatting on Facebook have become popular activities on this dominant social media outlet. Such integration and adoption of multiple functions on one single service might gradually modify users' perceptions of that platform's characteristics. Nevertheless, it is also likely that the notion of long tail will be applicable in the social media world. While we might see the emergence of some all- 
encompassing social media services, not all social media outlets can or have the resources to offer abundance features. In this case, the ability to play to its strength as perceived by the users becomes even more essential for a niche social media platform to be effective.

This study is limited by its generalizability as its respondents are opt-in consumers who were compensated by small premium rewards and thus might not be representative of the general population. Because of the comparative nature of the survey and the number of social media reviewed, the time to complete the survey was relatively long. Thus, there might be inertia in answering the comparative scales. Future research might examine the perceptions of various social media types in affecting advertising or branding effectiveness and the optimal combination of social media tools in reaching advertising goals considering their characteristics.

Table 1. Reliability of Social Media Characteristics

\begin{tabular}{|c|c|c|c|c|c|c|c|c|}
\hline \multirow[t]{2}{*}{ Variables } & \multirow[t]{2}{*}{ Items } & SNSs & Blogs & Wikis & Forum & $\begin{array}{l}\text { Content } \\
\text { Community }\end{array}$ & $\begin{array}{l}\text { Micro- } \\
\text { bloggings }\end{array}$ & $\begin{array}{l}\text { Social } \\
\text { Media }\end{array}$ \\
\hline & & $\alpha$ & $\alpha$ & $\alpha$ & $\alpha$ & $\alpha$ & $\alpha$ & $\alpha$ \\
\hline \multirow[t]{4}{*}{ Openness } & & .929 & .945 & .940 & .966 & .961 & .966 & .951 \\
\hline & $\begin{array}{l}\text { I feel I can receive other people's } \\
\text { comments easily. } \\
\text { I feel I can express my opinions } \\
\text { easily. }\end{array}$ & & & & & & & \\
\hline & $\begin{array}{l}\text { I feel I can exchange new ideas with } \\
\text { others openly. } \\
\text { I feel I can exchange information } \\
\text { openly. }\end{array}$ & & & & & & & \\
\hline & $\begin{array}{l}\text { Type of social media provide a good } \\
\text { environment for me to participate in } \\
\text { the things/communities I care about. }\end{array}$ & & & & & & & \\
\hline \multirow[t]{2}{*}{ Participation } & & .954 & .971 & .972 & .978 & .981 & .983 & .973 \\
\hline & $\begin{array}{l}\text { I feel I can take an active part in the } \\
\text { communities I care about. } \\
\text { I feel I can do my best to stimulate } \\
\text { the communities I care about. } \\
\text { I feel I can offer useful information } \\
\text { to the communities I care about. } \\
\text { I feel I can help and support the } \\
\text { communities I care about. } \\
\text { Type of social media provide a good }\end{array}$ & & & & & & & \\
\hline
\end{tabular}


environment for me to participate in the things/communities I care about.

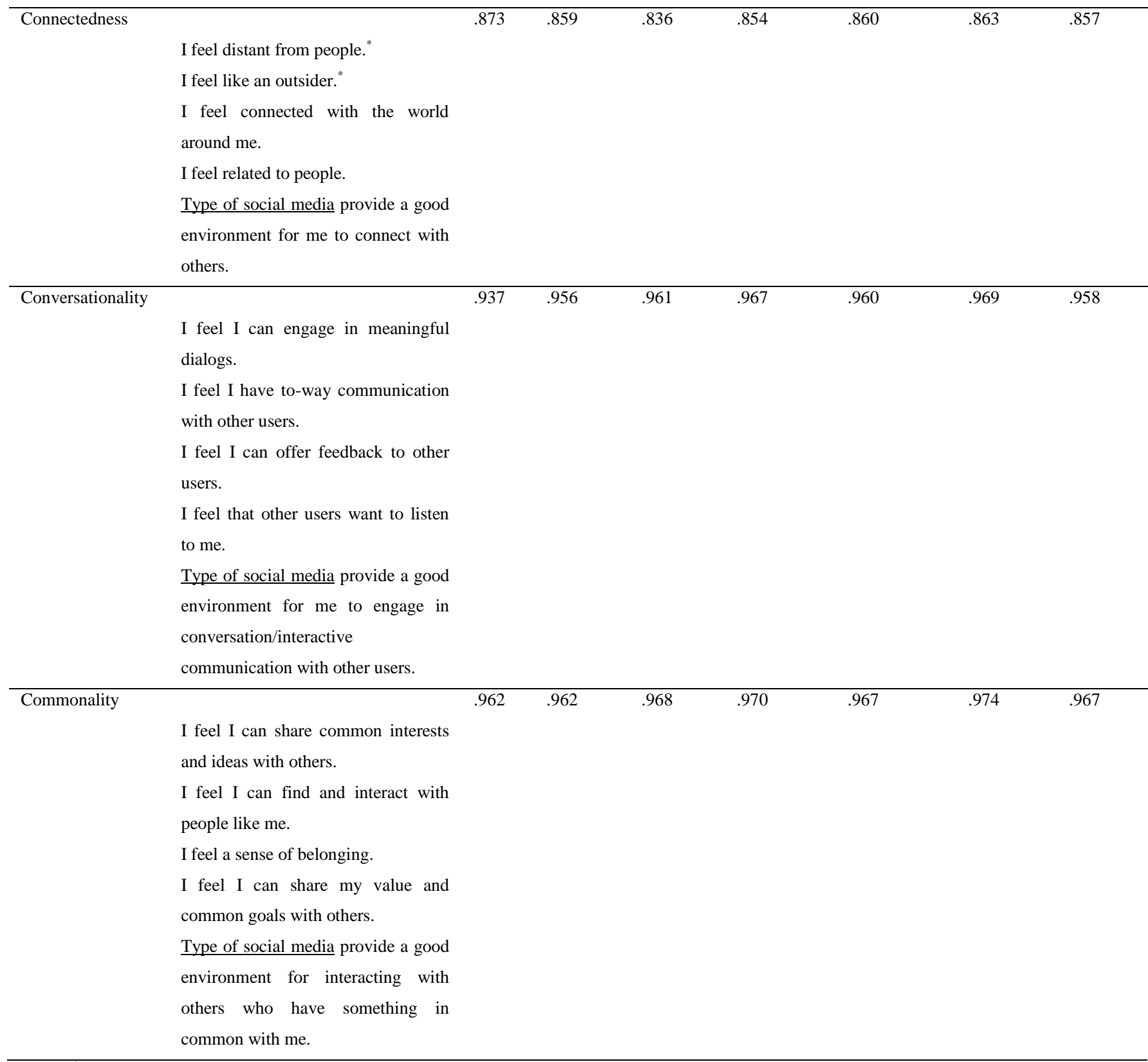


Figure 1: Comparison of Communal Media Characteristics by Social Media Openness

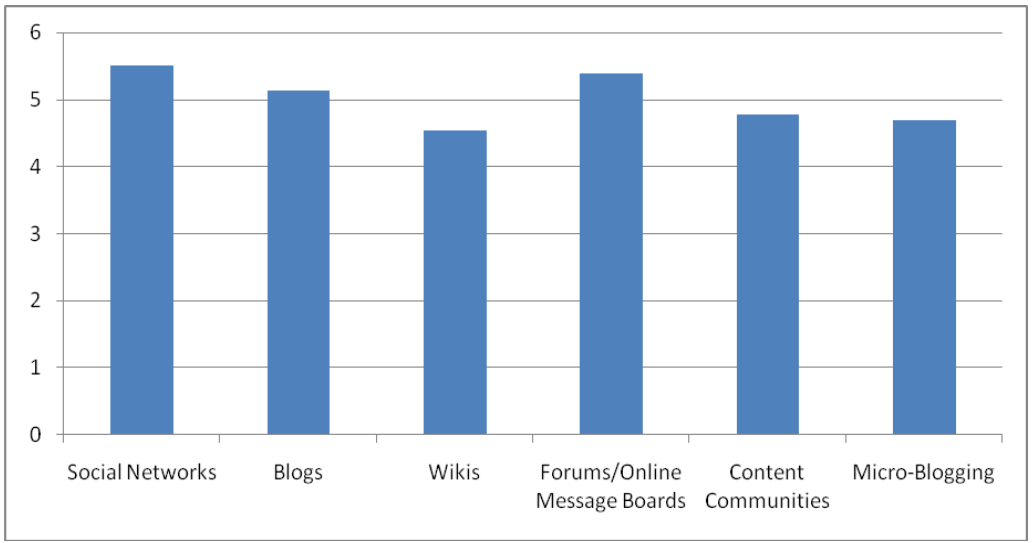

Participaton

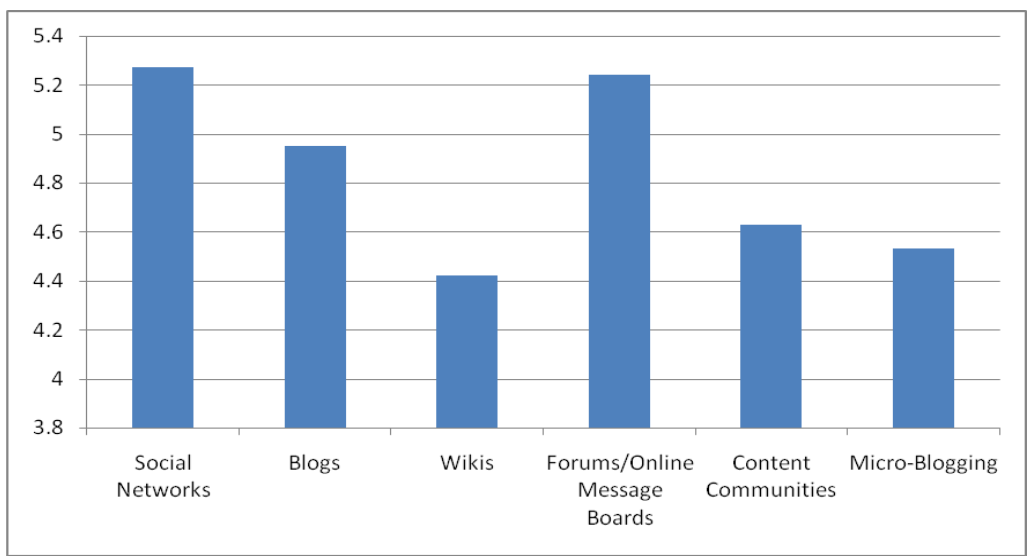

Connectedness

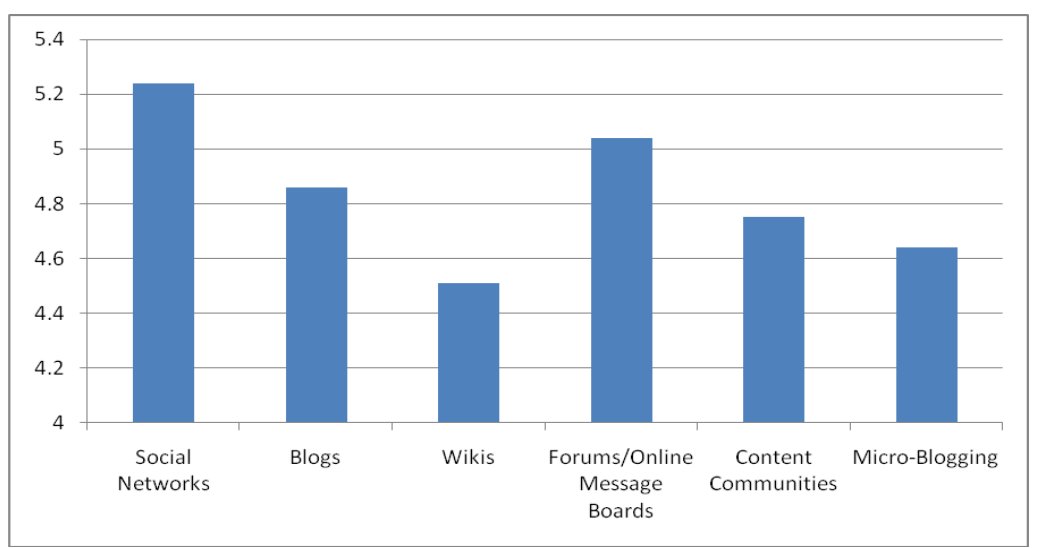




\section{Conversation}

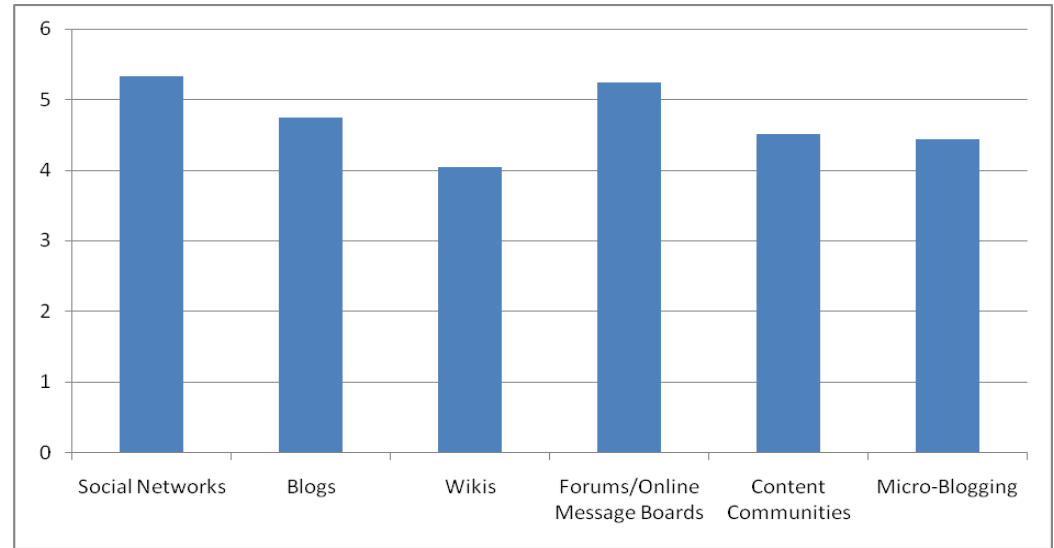

Commonality

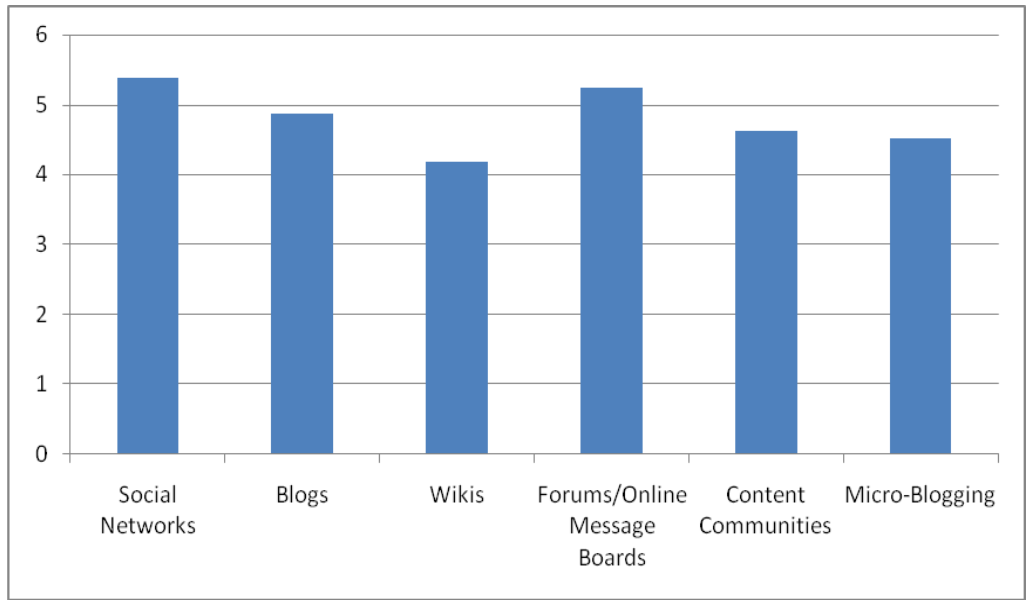

Table 2. Mean Scores of Communal Media Characteristics by Social Media Types

\begin{tabular}{|c|c|c|c|c|c|c|c|c|c|c|c|c|}
\hline & \multicolumn{2}{|c|}{$\begin{array}{l}\text { Social } \\
\text { Network }\end{array}$} & \multicolumn{2}{|l|}{ Blogs } & \multicolumn{2}{|c|}{ Wikis } & \multicolumn{2}{|c|}{ Forums } & \multicolumn{2}{|c|}{$\begin{array}{l}\text { Content } \\
\text { Communities }\end{array}$} & \multicolumn{2}{|c|}{$\begin{array}{l}\text { Micro- } \\
\text { Blogging }\end{array}$} \\
\hline & $M$ & $S D$ & $M$ & $S D$ & $M$ & $S D$ & $M$ & $S D$ & $M$ & $S D$ & $M$ & $S D$ \\
\hline Openness & 5.51 & 1.18 & 5.14 & 1.32 & 4.55 & 1.42 & 5.38 & 1.25 & 4.78 & 1.34 & 4.70 & 1.45 \\
\hline Participation & 5.27 & 1.21 & 4.95 & 1.38 & 4.43 & 1.48 & 5.24 & 1.33 & 4.64 & 1.41 & 4.54 & 1.51 \\
\hline Connectedness & 5.24 & 1.21 & 4.87 & 1.25 & 4.52 & 1.24 & 5.05 & 1.23 & 4.75 & 1.27 & 4.65 & 1.27 \\
\hline Conversationality & 5.33 & 1.21 & 4.75 & 1.39 & 4.04 & 1.53 & 5.25 & 1.27 & 4.51 & 1.43 & 4.65 & 1.53 \\
\hline Commonality & 5.38 & 1.30 & 4.88 & 1.36 & 4.20 & 1.52 & 5.25 & 1.31 & 4.63 & 1.40 & 4.53 & 1.52 \\
\hline
\end{tabular}


Table 3. Correlation Coefficients of Social Media Characteristics by Social Media Types

\begin{tabular}{|c|c|c|c|c|c|c|}
\hline & $\begin{array}{l}\text { Social } \\
\text { Network }\end{array}$ & Blogs & Wikis & Forums & $\begin{array}{l}\text { Content } \\
\text { Communities }\end{array}$ & $\begin{array}{l}\text { Micro- } \\
\text { Blogging }\end{array}$ \\
\hline Participation & & & & & & \\
\hline$\&$ & .810 & .835 & .813 & .871 & .888 & .915 \\
\hline Conversation & & & & & & \\
\hline Participation & & & & & & \\
\hline$\&$ & .816 & .869 & .825 & .891 & .868 & .921 \\
\hline Commonality & & & & & & \\
\hline Conversation & & & & & & \\
\hline$\&$ & .923 & .931 & .926 & .957 & 935 & .950 \\
\hline Commonality & & & & & & \\
\hline $\begin{array}{l}\text { Openness \& } \\
\text { Participation }\end{array}$ & -- & .865 & .893 & .897 & .866 & .903 \\
\hline $\begin{array}{l}\text { Openness \& } \\
\text { Conversation }\end{array}$ & -- & .806 & .809 & .851 & .816 & .879 \\
\hline $\begin{array}{l}\text { Openness \& } \\
\text { Commonality }\end{array}$ & -- & .833 & .800 & .849 & .816 & .868 \\
\hline
\end{tabular}




\section{Reference}

Baker, J. R., \& Moore, S. M. (2008). Distress, coping, and blogging: Comparing new Myspace users by their intention to blog. CyberPsychology \& Behavior, 11(1), 81-85. Ballard, C., \& Prine, R. (2002). Citizen perceptions of community policing: Comparing Internet and mail survey responses. Social Science Computer Review, 20, 485-493.

Barker, V. (2009). Older adolescents' motivations for social network site use: The influence of gender, group identity, and collective self-esteem. CyberPsychology \& Behavior, 12(2), 209-213.

Barnes, C. (2009). Social networking: Not just for youngsters anymore. Bar Leader, 33(3), 19.

Bernoff, J., Pflaum, C. N., \& Bowen, E. (2008). The growth of social technology adoption. Forrester Research Report, Cambridge, MA.

Boulos, M. N. K., Maramba, I., \& Wheeler, S. (2006). Wikis, blogs and podcasts: A new generation of Web-based tools for virtual collaborative clinical practice and education. BMC Medical Education, 6:41.

Boyd, D. M., \& Ellison, N. B. (2007). Social network sites: Definition, history, and scholarship. Journal of Computer-Mediated Communication, 13, 210-230.

Burgoon, J.K., Bonito, J.A., Bengtsson, B., Ramirez, A., Dunbar, N.E., \& Miczo, N. (2000). Testing the interactivity model: Processes, partner assessments, and the quality of collaborative work. Journal of Management Information Systems, 16(3), 33-56.

Cebeci, Z., \& Tekdal, M. (2006). Using podcasts as audio learning objects. Interdisciplinary Journal of Knowledge and Learning Objects, 2, 47-57.

Corbett, P. (January 5, 2009). 2009 Facebook demographics and statistics report: 276\% Growth in 35-54 year old users. iStrategyLabs. Retrieved January 2, 2010, from http://www.istrategylabs.com/2009/01/2009-facebook-demographics-and-statisticsreport-276-growth-in-35-54-year-old-users/

Drury, G. (2008). Opinion piece: Social media: Should marketers engage and how can it be done effectively? Journal of Direct, Data and Digital Marketing Practice, 9, 274-277.

Dykeman, D. (February 9, 2008). How do you define social media? Broadcasting Brain. Retrieved from October 9, 2009, from http://broadcasting-brain.com/2008/02/09/howdo-you-define-social-media/

Eisenberg, B. (November 7, 2008). Understanding and aligning the value of social media. Future Now. Retrieved December 10, 2009, from 
http://www.grokdotcom.com/2008/11/07/understanding-and-aligning-the-value-ofsocial-media/

Ellison, N. B., Steinfield, C., \& Lampe, C. (2007). The benefits of Facebook "friends": Social capital and college students' use of online social network sites. Journal of Computer-Mediated Communication, 12(4), 1143-1168.

eMarketer (January 18, 2011). Facebook drives US social network ad spending past \$3 billion in 2011. Retrieved Januaey 12, 2013, from http://www.emarketer.com/Article.aspx?R=1008180

Emigh, W., \& Herring, S. C. (2005). Collaborative authoring on the web: A genre analysis of online encyclopedias. Proceedings of the 38th Hawai'i International Conference on System Sciences (HICSS-38). Los Alamitos: IEEE Press. Retrieved March 10, 2010, from http://ella.slis.indiana.edu/ herring/wiki.pdf

Ha, L., \& James, E. L. (1998). Interactivity reexamined: A baseline analysis of early business Web sites. Journal of Broadcasting \& Electronic Media, 42(4), 456-473.

Hargittai, E. (2007). Whose space? Differences among users and non-users of social network sites. Journal of Computer-Mediated Communication, 13(1), 276-297.

The Huffington Post (October 4, 2012). Facebook has 1 billion users, Mark Zuckerberg announces in a status update. Retrieved October 10, 2012, from http://www.huffingtonpost.com/2012/10/04/facebook-1-billionusers_n_1938675.html?utm_hp_ref=technology

Java, A., Song, X., Finin, T., \& Tseng, B. (August, 2007). Why we twitter: Understanding microblogging usage and communities. Proceedings of the Joint 9th WEBKDD and 1st SNA-KDD Workshop 2007.

Joiner, R., Gavin, J., Duffield, J., Brosnan, M., Crook, C., Durndell, A., Maras, P., Miller, J., Scott, A. J., \& Lovatt, P. (2005). Gender, internet identification, and internet anxiety: Correlates of internet use. CyberPsychology \& Behavior, 8(4), 371-378.

Koh, J. \& Kim, D. (2004) Knowledge sharing in virtual communities: An e-business perspective. Expert Systems with Applications, 26(2), 155-166.

Langdridge, D. (2004). Introduction to research methods and data analysis in psychology. Harlow, England: Pearson Prentice Hall.

Larrumbide, A. (September 25, 2008). Cone finds that Americans expect companies to have a presence in social media. Cone Business in Social Media Research. Retrieved October 10, 2012, from http://www.coneinc.com/content1182 
Lee, R. M., Draper, M., \& Lee, S. (2001). Social connectedness, dysfunctional interpersonal behaviors, and psychological distress: Testing a mediator model. Journal of Counseling Psychology, 48(3), 310-318.

Lee, R. M., \& Robbins, S. B. (1998). The relationship between social connectedness and anxiety, self-esteem, and social identity. Journal of Counseling Psychology, 45(3), 338-345.

Lipsman, A. (June 4, 2009). Huffington post defies expectations, reaches new heights postelection. ComScore. Retrieved March 10, 2010, from http://blog.comscore.com/2009/06/huffington_post_visitors.html

Liu, Y. (2003). Developing a scale to measure the interactivity of websites. Journal of Advertising Research, 43(2), 207-216.

Liu, Y. \& Shrum, L. J. (2002). What is interactivity and is it always such a good thing? Implications of definition, person, and situation for the influence of interactivity on advertising effectiveness. Journal of Advertising, 31(4), 53-64.

Marchese, J. (June 5, 2007). Defining social media. Media Post. Retrieved October 9, 2009, from http://www.mediapost.com/publications/?fa=Articles.showArticle\&art_aid=61442

Marshall, J. (December 21, 2009). Most visited web site and most searched term in 2009 ? ClickZ. Retrieved January 2, 2010, from http://www.clickz.com/3635954

Mayfield, A. (2008). What is social media? iCrossing. Retrieved August 25, 2009, from

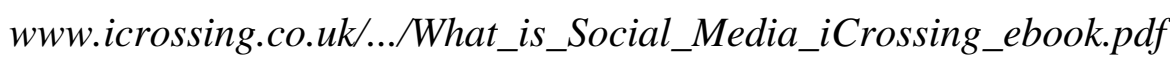

Meadows-Klue, D. (2007). Falling in love 2.0: Relationship marketing for the Facebook generation. Journal of Direct, Data \& Digital Marketing Practice, 9, 245-250.

Miller, C. C. (August 25, 2009). Who's driving Twitter's popularity? Not teens. New York Times. Retrieved October 20, 2009, from http://www.nytimes.com/2009/08/26/technology/internet/26twitter.html?_r=1

Myers, S. A., Knox, R. L., Pawlowski, D. R., \& Ropog, B. L. (1999). Perceived communication openness and functional communication skills among organizational peers. Communication Reports, 12, 71-83.

Nail, J. (January 12, 2009). Social media in 2009: A tale of two futures. Public Relations Tactics. Retrieved September 8, 2009, from http://www.prsa.org/SearchResults/view/7765/105/Social_media_in_2009_A_tale_of _two_futures 
Nielsen (March 9, 2009). Global faces and networked places: A Nielsen report on social networking's new global footprint. The Nielsen Company. Retrieved January 9, 2010, from blog.nielsen.com/nielsenwire/wp.../nielsen_globalfaces_mar09.pdf

Ostrow, A. (July 28, 2009). Number of social networking users has doubled since 2007. Mashable.com. Retrieved January 3, 2010, from http://mashable.com/2009/07/28/social-networking-users-us/

Paine, K. D. (2009). How to set benchmarks in social media: Exploratory research for social media, lessons learned. Paper presented the $12^{\text {th }}$ Annual International Public Relations Research Conference, Miami, FL.

Pew Research Center (December 22, 2003). America's online pursuits. Retrieved March 16, 2010, from http://www.pewinternet.org/Reports/2003/Americas-Online-Pursuits.aspx

Pew Research Center (November 2, 2005). Teen content creators and consumers. Retrieved March 15, 2010, from http://www.pewinternet.org/Reports/2005/Teen-ContentCreators-and-Consumers.aspx

Pew Research Center (January 7, 2007). Social networking websites and teens. Retrieved March 14, 2010, from http://www.pewinternet.org/Reports/2007/Social-NetworkingWebsites-and-Teens.aspx

Pew Research Center (January, 2009). Adults and social network websites. Retrieved March 14, 2010, from http://www.pewinternet.org/Reports/2009/Adults-and-SocialNetwork-Websites/1-Summary-of-findings/One-third-of-American-adult-internetusers-have-a-profile-on-an-online-social-network-site.aspx? $\mathrm{r}=1$

Pew Research Center (February 3, 2010). Social media and young adults. Retrieved March 15, 2010, from http://www.pewinternet.org/Reports/2010/Social-Media-and-YoungAdults.aspx

Pfeil, U., Zaphiris, P., \& Ang, C. S. (2006). Cultural differences in collaborative authoring of Wikipedia. Journal of Computer-Mediated Communication, 12(1), 88-113.

Pilch, C. (February 16, 2009). Social media marketing and web 2.0: What are they, and how can they help you bring in more business. Business West. Retrieved September 8, 2009, from http://businesswest.com/details.asp?id=1916

Raacke, J., \& Bonds-Raacke, J. (2008). MySpace and Facebook: Applying the uses andgratifications theory to exploring friend-networking sites. Cyberpsychology \& Behavior, 11(2), 169-174.

Rafaeli, S. (1988). Interactivity From new media to communication. In Hawkins, R., 
Wiemann, J. M., \& Pingree, S. (1988). Advancing communication science: Merging mass and interpersonal processes. Sage annual reviews of communication research, v. 16. (pp. 110-134), Newbury Park, Calif: Sage Publications.

Rogers, D. P. (1987). The development of a measure of perceived communication openness. The Journal of Business Communication, 24(4), 53-61.

Ross, C., Orr, E. S., Sisic, M., Arseneault, J. M., Simmering, M. G., \& Orr, R. R. (2009). Personality and motivations associated with Facebook use. Computers in Human Behavior, 25(2), 578-586.

Rowley, J. (2004). Just another channel? Marketing communications in e-business. Marketing Intelligence \& Planning, 22(1), 24-41.

Safko, L., \& Brake, D. K. (2009). The social media bible: Tactics, tools, and strategies for business success. Hoboken, N.J.: John Wiley \& Sons.

Schonlau, M., Fricker Jr., R. D., \& Elliott, M. N. (2002). Conducting Research Surveys via Email and the Web. Arlington: VA: RAND Publications.

Sharma, P. (November 28, 2008). Core characteristics of web 2.0 services. TechPluto. Retrieved October 10, 2009, from http://www.techpluto.com/web-20-services/

Stafford, L., Kline, S. K., \& Dimmick, J. (1999). Home e-mail: Relational maintenance and gratification opportunities. Journal of Broadcast and Electronic Media, 43(4), 659669.

Stelzner, M. A. (2009). Social media marketing industry report: How marketers are using social media to grow their businesses. WhitePaperSource.com. Retrieved October 29, 2009, from http://www.whitepapersource.com/socialmediamarketing/report/

Stephen, A. T., \& Galak, J. (2009). The complementary roles of traditional and social media in driving marketing performance. Social Science Research Network. Retrieved January 4, 2010, from http://ssrn.com/abstract=1480088

Steuer, J. (1992). Defining virtual reality: Dimensions determining telepresence. Journal of Communication, 42(4), 73-93.

Teixeira, R.A. (1992) The disappearing American voter. Washington, DC: The Brookings Institution.

Thomas, M. J. W. (2002). Learning within in coherent structures: The space of online discussion forums. Journal of Computer Assisted Learning, 18, 351-366.

Universal McCann (2008). Power to the people: Social media tracker Wave 3. Retrieved October 30, 2009, from http://www.scribd.com/doc/25109686/International-Social- 
Media-Research-Wave-3

Valenzuela, S., Park, N., \& Kee, K. F. (2009). Is there social capital in a social network site? Facebook use, and college students' life satisfaction, trust, and participation. Journal of Computer-Mediated Communication, 14(4), 875-901.

Van Grove, J. (March 18, 2010). What social media users want. Mashable.com. Retrieved March 19, 2010, from http://mashable.com/2010/03/18/social-media-sites-data/

Viégas, F. B., Wattenberg, M., \& Dave, K. (2004). Studying cooperation and conflict between authors with history flow visualizations. In E. Dykstra-Erickson \& M. Tscheligi (Eds.), Proceedings from ACM CHI 2004 Conference on Human Factors in Computing System (pp. 575-582). Vienna, Austria. Retrieved March 18, 2010, from http://web.media.mit.edu/ fviegas/papers/history_flow.pdf

Waters, R., Nuttall, C., \& Gelles, D. (February 26, 2009). Sweet to tweet. The Financial Times. Retrieved January 6, 2011, from http://www.ft.com/cms/s/0/5e1e10c0-043d11de-845b-000077b07658.html\#axzz1DCo0jIT4

Wellman, B. \& Gulia, M. (2003). Net surfers don't ride alone: Virtual communities as communities. In M. Smith \& P. Kollock (Eds.) Communities in cyberspace. London: Routledge.

Williamson, D. A. (November, 2009). PGs and social media: Much more than advertising. eMarketer. Retrieved January 6, 2010, from http://www.emarketer.com/Reports/All/Emarketer_2000620.aspx

Wimmer, R. D., \& Dominick, J. R. (2006). Mass media research: An introduction (38th Ed.). Belmont, CA: Wadsworth.

Wright, K. B. (2000). The communication of social support within an on-line community for older adults: A qualitative analysis of the SeniorNet community. Qualitative Research Reports in Communication, 1(2), 33-43. 